\title{
Correction: Impact of modified risk tobacco product claims on beliefs of US adults and adolescents
}

El-Toukhy S, Baig SA, Jeong M, et al. Impact of modified risk tobacco product claims on beliefs of US adults and adolescents. Tobacco Control 2018;27:s62-s69. doi:tobaccocontrol-2018-054315

The correct version of table 3 is as follows:

Table 3 Path coefficients from mediation analysis for the effects of lower risk and lower exposure claims on susceptibility to use MRTPs

\begin{tabular}{|c|c|c|c|c|c|c|c|c|c|c|}
\hline & \multicolumn{5}{|c|}{ Perceived quantity } & \multicolumn{5}{|c|}{ Perceived risk } \\
\hline & $a$ & $b$ & c & $c^{\prime}$ & Mediated effect & $a$ & $b$ & c & $c^{\prime}$ & Mediated effect \\
\hline \multicolumn{11}{|l|}{ Experiment 1} \\
\hline \multicolumn{11}{|l|}{ Adults ( $n=2352)$} \\
\hline Risk claim & $-0.17^{* *}$ & $-0.41^{* *}$ & $0.12^{*}$ & 0.05 & $0.07^{* *}$ & $-0.14^{* *}$ & $-0.34^{* *}$ & $0.12^{* *}$ & $0.08^{*}$ & $0.05^{* *}$ \\
\hline IQOS vs snus & $-0.28^{* *}$ & $-0.40^{* *}$ & $0.30^{* *}$ & $0.19^{* *}$ & $0.11^{* *}$ & -0.21 ** & $-0.33^{* *}$ & $0.30^{* *}$ & $0.23^{* *}$ & $0.07^{* *}$ \\
\hline E-cig vs snus & $-0.40^{* *}$ & $-0.40^{* *}$ & $0.30^{* *}$ & $0.14^{* *}$ & $0.16^{* *}$ & $-0.29^{* *}$ & $-0.33^{* *}$ & $0.30^{* *}$ & $0.20^{* *}$ & $0.09 * *$ \\
\hline \multicolumn{11}{|c|}{ Adolescents $(n=480)$} \\
\hline Risk claim & $-0.28^{* *}$ & $-0.17^{* *}$ & 0.02 & -0.02 & $0.05^{* *}$ & $-0.23^{*}$ & $-0.20^{* *}$ & 0.02 & -0.02 & $0.05^{*}$ \\
\hline IQOS vs snus & $-0.21^{*}$ & $-0.17^{* *}$ & 0.01 & -0.02 & $0.04^{* *}$ & $-0.18^{*}$ & $-0.20^{* *}$ & 0.01 & -0.02 & $0.04^{*}$ \\
\hline E-cig vs snus & $-0.33^{* *}$ & $-0.17^{* *}$ & 0.03 & -0.03 & $0.06^{* *}$ & $-0.35^{* *}$ & $-0.20^{* *}$ & 0.03 & -0.04 & $0.07^{* *}$ \\
\hline \multicolumn{11}{|l|}{ Experiment 2} \\
\hline \multicolumn{11}{|l|}{ Adults $(n=2445)$} \\
\hline Exposure claim & -0.31 ** & $-0.29^{* *}$ & 0.06 & -0.03 & $0.09 * *$ & $-0.18^{* *}$ & $-0.31^{* *}$ & 0.06 & 0.01 & $0.06^{* *}$ \\
\hline IQOS vs snus & $-0.12^{*}$ & $-0.27^{* *}$ & $0.31^{* *}$ & $0.27^{* *}$ & $0.03^{* *}$ & $-0.12^{*}$ & $-0.30^{* *}$ & $0.31^{* *}$ & $0.27^{* *}$ & $0.04^{*}$ \\
\hline E-cig vs snus & $-0.15^{* *}$ & $-0.27^{* *}$ & $0.27^{* *}$ & $0.23^{* *}$ & $0.04^{* *}$ & $-0.17^{* *}$ & $-0.30^{* *}$ & $0.27^{* *}$ & $0.22^{* *}$ & $0.05^{* *}$ \\
\hline \multicolumn{11}{|c|}{ Adolescents $(n=489)$} \\
\hline Exposure claim & $-0.39^{* *}$ & $-0.19^{* *}$ & 0.01 & -0.07 & $0.07^{* *}$ & $-0.19^{*}$ & $-0.18^{* *}$ & 0.01 & -0.03 & $0.04^{*}$ \\
\hline IQOS vs snus & $-0.21^{*}$ & $-0.17^{* *}$ & 0.05 & 0.01 & $0.04^{*}$ & $-0.21 *$ & $-0.18^{* *}$ & 0.05 & 0.01 & $0.04^{*}$ \\
\hline E-cig vs snus & $-0.20^{*}$ & $-0.17^{* *}$ & 0.08 & 0.05 & $0.03^{*}$ & -0.21 * & $-0.18^{* *}$ & 0.08 & 0.04 & $0.04^{*}$ \\
\hline
\end{tabular}

Open access This is an open access article distributed in accordance with the Creative Commons Attribution Non Commercial (CC BY-NC 4.0) license, which permits others to distribute, remix, adapt, build upon this work noncommercially, and license their derivative works on different terms, provided the original work is properly cited and the use is non-commercial. See: http://creativecommons.org/licenses/by-nc/4.0/

(C) Author(s) (or their employer(s)) 2020. Re-use permitted under CC BY-NC. No commercial re-use. See rights and permissions. Published by BMJ.

Tob Control 2020;29:360. doi:10.1136/tobaccocontrol-2018-054315corr1

D) Check for updates 